PROFESI (Profesional Islam)

Media Publikasi Penelitian; 2018; Volume 15; No 2.

Website: ejournal.stikespku.ac.id

\title{
Pengetahuan Risiko, Perilaku Pencegahan Anemia dan Kadar Hemoglobin pada Remaja Putri
}

\author{
Nur Ainun Hasyim, Mutalazimah*, Muwakhidah \\ Prodi Ilmu Gizi, Fakultas Ilmu Kesehatan, Universitas Muhammadiyah Surakarta \\ *email: mutalazimah@ums.ac.id
}

\begin{abstract}
Kata Kunci
Pengetahuan risiko, Perilaku pencegahan anemia,

Kadar hemoglobin
\end{abstract}

\begin{abstract}
Abstrak
Anemia masih menjadi salah satu masalah kesehatan pada remaja di Indonesia. Remaja putri berisiko terkena anemia sepuluh kali lipat dibandingkan dengan remaja putra. Akibat jangka pendek anemia pada remaja yaitu mudah lelah, lemah, letih dan lesu. Akibat jangka panjang apabila hamil dapat menyebabkan BBLR, angka kematian perinatal, prematuritas. Anemia disebabkan oleh beberapa hal, seperti kurangnya pengetahuan risiko anemia dan perilaku pencegahan anemia. Menganalisis hubungan pengetahuan risiko anemia dan perilaku pencegahan anemia dengan kadar hemoglobin pada remaja putri di SMK Negeri 1 Sukoharjo. Jenis penelitian ini termasuk observasional dengan pendekatan cross sectional.Subyek penelitian sebanyak 54 remaja putri yang dipilih secara simple random sampling. Pengetahuan risiko anemia dan perilaku pencegahan anemia diukur dengan kuesioner yang telah teruji reliablitasnya. Kadar hemoglobin diukur menggunakan alat Hemocue. Analisis statistik menggunakan uji korelasi Pearson product moment. Rata-rata nilai pengetahuan risiko anemia pada remaja putri adalah 69.7; rata-rata skor perilaku pencegahan anemia adalah 27.1; dan rata-rata kadar hemoglobin remaja putri adalah $11.6 \mathrm{~g} / \mathrm{dL}$. Ada hubungan antara pengetahuan risiko anemia dengan kadar hemoglobin pada remaja putri $(p=0.001)$ dan tidak ada hubungan antara perilaku pencegahan anemia dengan kadar hemoglobin pada remaja putri $(p=0.481)$. Kadar $\mathrm{Hb}$ remaja putri dapat dioptimalkan melalui peningkatan pengetahuan risiko dan perilaku pencegahan anemia.
\end{abstract}

\section{The Knowledge of Anemia Risk, Prevention Behavior of Anemia, and Hemoglobin Levels on Adolescent Girls}

\section{Keywords}

Knowledge Of Anemia Risk, Anemia Prevention Behavior, Hemoglobin Levels, Adolescent Girls.

\begin{abstract}
Anemia is still one health problem in adolescents in Indonesia. Adolescent girls are at risk of developing anemia than young men. Short-term consequences of anemia in adolescents are easily tired, weak, and lethargic. While long-term consequense in pre pregnant women can impact to birth outcome such as low birth weight, perinatal mortality, prematurity. Anemia is caused by several factors, such as a lack of knowledge of anemia risk and prevention behavior of anemia. Analyzing the correlation between knowledge of anemia risk, prevention behavior of anemia and hemoglobin level on adolescent girls at Vocational High School 1 of Sukoharjo is the aim of this study. This study was an observational study with cross sectional method. The research subjects were 54 adolescent girls chosen by simply random sampling. The knowledge of anemia risk and prevention behavior of anemia was measured by answering the questionnaire, and hemoglobin level was measured using a hemocue device. Statistical analysis used the correlation test of
\end{abstract}


PROFESI (Profesional Islam)

Media Publikasi Penelitian; 2018; Volume 15; No 2.

Website: ejournal.stikespku.ac.id

Pearson Product moment. The average score of knowledge of anemia risk was 69.7; the average score of anemia prevention behavior was 27.1; and the average of hemoglobin level was 11.6; g/dL. There was correlation between knowledge of anemia risk and hemoglobin levels in adolescent girls $(p=0.001)$ and there was no correlation between prevention behavior of anemia and hemoglobin levels in adolescent girls $(p=0.481)$. Hemoglobin levels could be optimized by improve knowledge of risk and prevention behavior of anemia.

\section{PENDAHULUAN}

Anemia gizi besi adalah anemia yang timbul akibat berkurangnya penyediaan besi untuk proses pembentukan sel darah merah, karena cadangan zat besi kosong sehingga pembentukan hemoglobin berkurang (Sudoyo et al., 2006). Berdasarkan hasil Riset Kesehatan Dasar tahun 2013, didapatkan hasil prevalensi anemia pada remaja putri umur 15-24 tahun adalah 18,4\% (Kemenkes RI, 2013). Berdasarkan hasil penelitian sebelumnya ditemukan prevalensi kejadian anemia di SMK Negeri 1 Kabupaten Sukoharjo pada remaja putri sebesar 38,9\% (Setyaningrum \& Mutalazimah, 2016).

Remaja putri yang telah mengalami menstruasi merupakan salah satu kelompok WUS dan merupakan masa transisi dan anak-anak menuju dewasa yang berpeluang meningkatnya aktifitas kehidupan sosial dan kesibukan, sehingga mempengaruhi kebiasaan yang cenderung mengkonsumi makanan cepat saji, praktis, namun rendah kandungan gizi (Kristianti et al., 2009). Kurangnya kandungan zat gizi dalam makanan berisiko menyebabkan anemia. Anemia pada remaja didefinisikan sebagai suatu keadaan kadar hemoglobin $(\mathrm{Hb})$ di dalam darah kurang dan angka normal sesuai dengan kelompok jenis kelamin dan umur. Nilai batas ambang anemia berdasarkan ketetapan WHO untuk remaja wanita adalah $12 \mathrm{~g} / \mathrm{dL}$ sedangkan untuk laki-laki $13 \mathrm{~g} / \mathrm{dL}$ (Andriyani \& Bambang, 2014). Anemia pada remaja putri berdampak pada menurunnya produktivitas kerja atau kemampuan akademis, dapat menganggu pertumbuhan, daya tahan tubuh menurun sehingga mudah terserang penyakit (Syatriani \& Aryani, 2010). Menurut Hidayati (2008), akibat jangka panjang dari anemia pada remaja putri yaitu BBLR, prematuritas, angka kematian perinatal, dan risiko kematian martenal. Sedangkan jangka pendek adalah mudah lelah, letih, lesu, dan lemah.

Menurut (Tashara et al., 2015), faktor yang melatarbelakangi tingginya prevalensi anemia di negara berkembang,adalah keadaan sosial, perilaku, kurang asupan zat besi, dan pengetahuan tentang anemia. Pengetahuan memegang peranan penting dalam kejadian anemia, bila pengetahuan tentang anemia rendah maka kejadian anemia pada remaja putri akan meningkat, hal ini sesuai dengan hasil penelitian yang dilakukan oleh Martini (2015) di MAN 1 Metro Tanjung Karang, yang menunjukkan bahwa remaja putri dengan pengetahuan yang kurang mempunyai risiko 2,3 kali mengalami anemia dibandingkan dengan remaja yang berpengetahuan baik.

Hasil survey yang dilakukan oleh Puskesmas Bendosari di SMK Negeri 1 Sukoharjo pada tahun 2014 menunjukkan bahwa dari 100 sampel remaja putri yang diperiksa, sebanyak 39\% diantaranya mengalami anemia. Berdasarkan masalah di atas maka peneliti tertarik untuk meneliti hubungan pengetahuan risiko anemia dan perilaku pencegahan anemia dengan kadar hemoglobin pada remaja putri di SMK Negeri 1 Sukoharjo. Tujuan penelitian secara umum adalah untuk menganalisis hubungan pengetahuan risiko anemia dan perilaku pencegahan anemia dengan kadar hemoglobin pada remaja putri di SMK Negeri 1 Sukoharjo.

\section{METODE PENELITIAN}

Penelitian ini merupakan jenis penelitian observasional dengan rancangan cross sectional yang dilaksanakan pada bulan April 2017. Lokasi penelitian dilakukan di SMK Negeri 1 Sukoharjo. Populasi penelitian adalah siswi kelas XI dengan jumlah sampel 54 sampel. Pengambilan sampel menggunakan teknik simple random sampling. Kriteria inklusi pada penelitian ini adalah seluruh siswi kelas XI, siswi dalam keadaan sehat, dan tidak sedang dalam keadaan menstruasi saat pengambilan darah. Kriteria eksklusi pada penelitian ini adalah siswi yang tidak masuk sekolah saat penelitian dan mengkonsumsi tablet tambah 
darah. Variabel bebas dalam penelitian ini adalah pengetahuan risiko anemia, perilaku pencegahan anemia dan kadar hemoglobin sebagai variabel terikat.

Teknik pengumpulan data identitas responden dilakukan dengan cara wawancara terstruktur menggunakan kuesioner. Data pengetahuan risiko anemia dan perilaku pencegahan anemia dikumpulkan menggunakan kuesioner dengan skala likert yang sudah diuji reliabilitas dengan indikator item-total correlation (20 item pengetahuan risiko anemia dan 18 item perilaku pencegahan anemia dinyatakan reliabel dengan nilai $r>0,3$ ) dan inter-item correlation (koefisien Cronbach's alpha juga dinyatakan reliabel dengan nilai koefisien alpha $>0,7$ yakni pada variabel pengetahuan risiko anemia sebesar 0,926 dan pada variabel perilaku pencegahan anemia sebesar 0,916). Prosedur penskalaan ordinal pada likert menjadi interval melalui summated rating scale dengan pendekatan interpretasi $z$-score. Data kadar hemoglobin diperoleh dengan cara pengambilan sampel darah oleh petugas analis kesehatan Puskesmas Bendosari dengan menggunakan metode Cyanmethemoglobin dengan alat Hemocue.

Analisis univariat dilakukan dengan mendeskripsikan skor pengetahuan risiko, skor perilaku pencegahan anemia dan kadar $\mathrm{Hb}$ yang disajikan melalui nilai rata-rata, standar deviasi, nilai minimal dan nilai maksimal. Selain itu menyajikan dalam bentuk tabel distribusi frekuensi berupa kategori skor pengetahuan risiko dan skor perilaku pencegahan anemia berdasarkan cut off point nilai rata-rata dari skor tersebut. Sementara itu kategori kadar $\mathrm{Hb}$ (anemia atau tidak anemia) didasarkan pada cut off point $12 \mathrm{gr} / \mathrm{dL}$. Analisis bivariat diawali dengan uji normalitas data menggunakan uji Kolmogorov-Smirnov dan uji hubungan menggunakan uji korelasi Pearson product moment karena data berdistribusi normal.

\section{HASIL DAN PEMBAHASAN}

Hasil penelitian menunjukkan bahwa kisaran umur responden pada penelitian ini adalah 15-17 tahun. Umur memiliki keeratan hubungan dengan kejadian anemia terutama pada remaja putri, pada umur ini remaja putri biasanya akan melakukan diet karena ingin langsing dan mengalami menstruasi setiap bulan sehingga memiliki risiko terjadinya anemia lebih besar. Sejalan dengan penelitian yang dilakukan oleh (Dwiriani et al., 2011) bahwa seiring dengan meningkatnya usia remaja semakin mengarah pada kondisi defisiensi zat besi, hal ini berhubungan dengan peningkatan kebutuhan zat besi selama usia remaja dengan nilai $\mathrm{p}=0,036$ dan $\mathrm{r}=0,198$. Menurut hasil penelitian yang dilakukan Iragashi et al., (2012) di Jepang, remaja putri usia 12-16 tahun memiliki prevalensi anemia lebih besar, yaitu $1,21 \%$ daripada remaja laki-laki sebesar $0,27 \%$, sedangkan di Indonesia, remaja perempuan memiliki risiko terkena anemia sepuluh kali lebih besar dibandingkan dengan remaja laki-laki (Briawan, 2014).

Tabel 1. Distribusi Subjek Berdasarkan Kategori Pengetahuan Risiko, Perilaku Pencegahan Anemia dan Kadar Hb

\begin{tabular}{lcc}
\hline \multicolumn{1}{c}{ Variabel } & $\mathrm{n}$ & $\%$ \\
\hline $\begin{array}{l}\text { Pengetahuan risiko anemia } \\
\quad \text { Baik }\end{array}$ & 21 & 38,9 \\
$\quad$ Kurang & 33 & 61,1 \\
Perilaku pencegahan anemia & & \\
$\quad$ Kurang & 1 & 1,9 \\
$\quad$ Sedang & 53 & 98,1 \\
Kadar Hb & & \\
$\quad$ Anemia & 32 & 59,3 \\
$\quad$ Tidak anemia & 22 & 40,7 \\
\hline
\end{tabular}

Menyimak data yang tersaji pada Tabel 1., bahwa sebagian besar remaja putri memiliki pengetahuan resiko anemia dengan kategori kurang $(61,1 \%)$. Hasil penelitian ini tidak jauh berbeda dengan penelitian Fajriyah \& Fitriyanto (2016) menunjukkan $64,3 \%$ remaja putri yang berpengetahuan rendah. Menurut Husna \& Fatmawati (2015) remaja dengan pengetahuan anemia rendah akan mempengaruhi kebiasaan yang kurang baik dalam memilih makanan dan mencegah masalah kesehatan terutama anemia sehingga masalah anemia pada remaja akan meningkat. Pengetahuan remaja putri yang kurang tentang risiko anemia akan berdampak pada status kesehatannya. Risiko yang dapat ditimbulkan yaitu kelelahan, badan lemah, penurunan produktivitas kerja, penurunan fungsi kognitif, dan bahkan berisiko menderita anemia pada kehamilan di masa yang akan datang (Hapzah \& Yulita, 2012). 
PROFESI (Profesional Islam)

Media Publikasi Penelitian; 2018; Volume 15; No 2.

Website: ejournal.stikespku.ac.id

Hampir keseluruhan responden memiliki perilaku pencegahan anemia yang tergolong dalam kategori sedang sebesar $98,1 \%$. Menurut hasil penelitian yang dilakukan oleh Caturiyantiningtiyas (2015) remaja putri yang memiliki perilaku kurang memiliki risiko 0,80 kali lebih besar menderita anemia. Ada fakta dari penelitian ini bahwa 59,3\% remaja putri mengalami anemia, menurut hasil pemeriksaan yang dilakukan Puskesmas Bendosari (2014) remaja putri mengalami anemia sebesar $39 \%$ dan hasil penelitian sebelumnya di SMK Negeri I Sukoharjo yang menemukan angka anemia sebesar 38,9\% (Setyaningrum \& Mutalazimah, 2016). Hal ini menunjukkan ada indikasi bahwa anemia pada remaja putri mengalami peningkatan dan masih menjadi masalah di Indonesia, karena berdasarkan ketetapan WHO, jika dalam suatu wilayah ditemukan prevalensi $>40 \%$ maka terdapat masalah kesehatan masyarakat (WHO, 2005).

Tabel 2. Statistik Deskriptif Pengetahuan Risiko, Perilaku Pencegahan Anemia dan Kadar $\mathrm{Hb}$

\begin{tabular}{lcc}
\hline \multicolumn{1}{c}{ Variabel } & rerata \pm SD & min-maks. \\
\hline $\begin{array}{l}\text { Skor pengetahuan } \\
\text { risiko anemia }\end{array}$ & $69,7 \pm 15,5$ & $40-95$ \\
$\begin{array}{l}\text { Skor perilaku } \\
\text { pencegahan }\end{array}$ & $27,1 \pm 4,0$ & $15,6-36,9$ \\
$\begin{array}{l}\text { anemia } \\
\text { Kadar Hb }\end{array}$ & $11,6 \pm 1,4$ & $8,0-14,5$ \\
\hline
\end{tabular}

Tabel 2. menunjukkan bahwa rata-rata skor pengetahuan risiko anemia remaja putri sebesar $69,7 \pm 15,5$. Bila dibandingkan dengan penelitian lain, hasil penelitian ini tidak berbeda jauh dengan penelitian yang dilakukan oleh Caturiyantiningtiyas (2015) menunjukkan hasil rata-rata pengetahuan $61,87 \pm 8,19$. Pengetahuan risiko anemia tergolong kategori baik jika jumlah skor pengetahuan $\geq 69,7$; sementara pengetahuan risiko anemia tergolong kurang, jika nilai $<69,7$. Pengetahuan merupakan salah satu faktor predisposisi yang penting. Remaja putri yang kurang pengetahuan tentang anemia akan berisiko menderita anemia (Martini, 2015). Remaja putri akan kehilangan zat besi hal ini dikarenakan remaja putri mengalami menstruasi setiap bulan sehingga kebutuhan zat besi meningkat (Iragashi et al., 2012). Sementara itu hasil rata-rata skor perilaku pencegahan anemia remaja putri sebesar $27,1 \pm 4,0$. Perilaku pencegahan anemia pada remaja tergolong baik jika jumlah nilai $\geq 27,1$ dan tegolong kurang jika $<27,1$. Nilai rata-rata

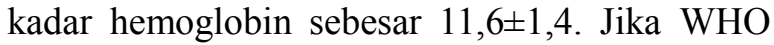
(2011) menetapkan, remaja tergolong anemia jika kadar hemoglobin $\geq 12$ gr/dL dan tegolong tidak anemia jika kadar hemoglobin $<12$ gr/dL, maka dilihat dari nilai rata-rata kadar $\mathrm{Hb}$ pada responden dibawah standar WHO.

Berdasarkan hasil uji data statistik menggunakan uji korelasi Pearson product moment diperoleh nilai $p=0,001$. Hal ini menunjukkan ada hubungan signifikan antara skor pengetahuan risiko anemia dengan kadar hemoglobin pada remaja putri di SMK Negeri 1 Sukoharjo. Penelitian ini sejalan dengan penelitian yang dilakukan oleh Caturiyantiningtiyas (2015) yang menyatakan bahwa ada hubungan yang signifikan antara tingkat pengetahuan dengan kadar hemoglobin pada remaja di SMA Negeri 1 Polokarto Kabupaten Sukoharjo. Pengetahuan yang cukup diharapkan dapat merubah perilaku memilih makanan menjadi lebih benar (Kusumawati \& Mutalazimah, 2004).

Pengetahuan memegang peranan penting dalam kejadian anemia, dengan pengetahuan tentang risiko anemia yang rendah maka kejadian anemia pada remaja putri akan meningkat. Pengetahuan yang kurang akan zat gizi menyebabkan kurangnya kecukupan mengkonsumsi sumber makanan yang mengandung zat besi yang berakibat rendahnya kadar hemoglobin (Listiana, 2016). Hasil penelitian yang dilakukan oleh Syatriani \& Aryani (2010) bahwa remaja putri yang mengkonsumsi zat besi kurang berisiko 276 kali lebih besar menderita anemia dengan nilai $\mathrm{p}=0,002$. Konsekuensi kesehatan yang ditimbulkan akibat defisiensi zat besi bagi remaja putri meliputi kelahiran prematur, berat badan lahir rendah, infeksi, dan peningkatan risiko keinatian, perkembangan fisik, gangguan kognitif yang mengakibatkan prestasi sekolah yang buruk (Masthalina et al., 2015).

Kadar hemoglobin remaja putri selain berkaitan dengan pengetahuan terhadap risiko anemia, juga berkaitan dengan perilaku pencegahan anemia, namun hasil uji korelasi Pearson product moment diperoleh nilai $\mathrm{p}=0,481$; yang berarti tidak ada hubungan antara perilaku pencegahan anemia dengan kadar hemoglobin pada remaja 
putri di SMK Negeri 1 Sukoharjo. Hasil penelitian ini sejalan dengan penelitian yang dilakukan oleh Setiawan (2006) bahwa tidak ada hubungan perilaku remaja putri dalam pencegahan anemia gizi di Madrasah Aliyah Al-Anwar Pondok Pesanten Poculgowang Diwek Kabupaten Jombang dengan nilai $p=0,637$. Hal ini tidak jauh berbeda dengan penelitian yang dilakukan oleh Lestari et al., (2015) bahwa salah satu faktor pencegahan anemia dipengaruhi oleh faktor eksternal yaitu lingkungan, selain itu juga motivasi sebagai faktor internal. Kurangnya motivasi dan kesadaran pada remaja putri yang rendah sehingga kemampuan atau perilaku dalam mencegah anemia juga akan rendah.

Hasil penelitian ini tidak sejalan dengan penelitian yang dilakukan oleh Tashara et al., (2015) bahwa pengetahuan memiliki hubungan yang signifikan dengan perilaku dalam mencegah anemia. Peningkatan pengetahuan tidak selalu menyebabkan perubahan perilaku, sehingga remaja putri dengan pengetahuan baik belum menjamin praktik terhadap pencegahan anemia juga baik (Farida, 2007). Perilaku yang kurang baik seperti aktivitas yang terlalu berlebihan pada remaja putri dan tidak diimbangi dengan pola makan dan istirahat, maka akan mempengaruhi proses pembentukan hemoglobin tidak optimal (Suryani et al., 2016). Upaya pencegahan anemia dapat dilakukan dengan tiga pendekatan dasar yaitu memperkaya asupan zat besi, mengkonsumsi tablet tambah darah sebelum dan selama menstruasi, serta peran petugas kesehatan dalam memberikan informasi cara pencegahan anemia (Tarwoto, 2010).

\section{SIMPULAN}

Ada hubungan pengetahuan risiko anemia dengan kadar hemoglobin pada remaja putri di SMK Negeri 1 Sukoharjo. Tidak ada hubungan perilaku pencegahan anemia dengan kadar hemoglobin pada remaja putri di SMK Negeri 1 Sukoharjo. Implikasi hasil kebijakan program gizi masyarakat yaitu masih diperlukan upaya untuk meningkatkan pengetahuan risiko anemia dan meningkatkan perilaku pencegahan anemia pada remaja putri melalui edukasi gizi dengan begitu dapat mengurangi risiko anemia pada remaja putri.

\section{REFERENSI}

Andriyani, M \& Bambang, W. (2014). Pengantar Gizi Masyarakat. Jakarta: Kencana Prenada Media Group.

Briawan, D. (2014). Anemia Masalah Gizi pada Remaja. Jakarta: EGC.

Caturiyantiningtiyas, T. (2015). Hubungan Antara Pengetahuan, Sikap dan Perilaku dengan Kejadian Anemia Remaja utri X dan XI SMA Negeri 1 Polokarto. Naskah Publikasi.

Dwiriani, C. M., R., \& Hardinsyah., Riyadi, H., Martianto, D. (2011). Pengarum Pemberian Zat Multi Gizi Mikro dan Pendidikan Gizi terhadap Pengetahuan Gizi, Pemenuhan Zat Gizi dan Status Besi Remaja Putri. Jurnal Gizi Dan Pangan, 6(3), 171-177.

Fajriyah, N. N \& Fitriyanto, M. L. H. (2016). Gambaran Tingkat Pengetahuan tentang Anemia pada Remaja Putri. Jurrnal Ilmiah Kesehatan, IX(1), 1-6.

Farida, I. (2007). Determinan Kejadian Anemia pada Remaja Putri di Kecamatan Gebog Kabupaten Kudus. Thesis Universitas Diponegoro.

Hapzah., \& Yulita, R. (2012). Hubungan Tingkat Pengetahuan dan Status Gizi terhadap Kejadian Anemia Remaja Putri pada Siswi Kelas III di SMAN 1 Tinambung Kabupaten Polewali Mandar. Media Gizi Pangan, XIII(1), 20-25.

Hidayati, R. (2008). Asuhan Keperawatan pada Kehamilan Fisiologi dan Patologis. Jakarta: Saldmba Medika.

Husna, U \& Fatmawati, R. (2015). Tentang Anemia Dengan Pola Makan ( Relationship of Knowledge About Anemia on Young Women With Dietary ). Profesional Islam, 12(2), 52-57.

Iragashi, T., Itoh, Y., Maeda, M. (2012). Mean Hemoglobin Levels in Venous Blood Samples and Prevalence of Anemia in Japanese Elementary and Junior High School Students. Journal Nippon 
PROFESI (Profesional Islam)

Media Publikasi Penelitian; 2018; Volume 15; No 2.

Website: ejournal.stikespku.ac.id

Medical School, 79(3).

Kemenkes RI. (2013). Riset Kesehatan Dasar Tahun 2013. Jakarta.

Kristianti, N., Sarbini, D., \& Mutalazimah, M. (2009). Hubungan Pengetahuan Gizi Dan Frekuensi Konsumsi Fast Food Dengan Status Gizi Siswa SMA Negeri 4 Surakarta. Jurnal Kesehatan, 2, 39-48.

Kusumawati, Y., \& Mutalazimah, M. (2004). Hubungan Pendidikan dan Pengetahuan Gizi Ibu dengan Berat Bayi Lahir di RSUD dr. Moewardi Surakarta. Info Kesehatan, 8(1), 1-9.

Lestari, P., Widardo, W., \& Mulyani, S. (2015). Pengetahuan Berhubungan dengan Konsumsi Tablet Fe Saat Menstruasi pada Remaja Putri di SMAN 2 Banguntapan Bantul. Jurnal Ners Dan Kebidanan Indonesia, 3(3), 145-149. https://doi.org/10.21927/jnki.2015.3(3).1 45-149

Listiana, A. (2016). Analisis faktor-faktor yang berhubungan dengan kejadian anemia gizi besi pada remaja putri di smkn 1 terbanggi besar lampung tengah. Jurnal Kesehatan, VII(3), 455-469.

Martini. (2015). Faktor-Faktor Yang Berhubungan Dengan Kejadian Anemia pada Remaja Putri di MAN 1 Metro. Jurnal Kesehatan Metro Sai Wawai Volume, $\operatorname{VIII}(1)$.

Masthalina, H., Laraeni, Y., \& Dahlia, Y. P. (2015). Pola Konsumsi (Faktor Inhibitor dan Enhancer $\mathrm{Fe}$ ) Terhadap Status Anemia Remaja Putri. Jurnal Kesehatan Masyarakat, $\quad 11(1), \quad 80-86$. https://doi.org/ISSN 1858-1196

Setiawan, D. (2006). Perilaku remaja putri dalam pencegahan anemia gizi. ADLN Perpustakaan Universitas Airlangga.
Setyaningrum, A. D., \& Mutalazimah, M. (2016). Hubungan Antara Indikator Pemeriksaan Klinis Dan Biofisik Sebagai Variabel Prediktor Dengan Penentuan Status Anemia Pada Siswi Di SMK Negeri 1 Sukoharjo. E-Paper. Retrieved from http://eprints.ums.ac.id/44446/3/HALAM AN DEPAN.pdf

Sudoyo, A., W., Bambang S., I. A. (2006). Ilmu Penyakit Dalam. Jakarta: Fakultas Kedokteran Universitas Indonesia.

Suryani, D., Hafiani, R., Junita, R. (2016). Analisis Pola Makan dan Anemia Gizi Besi pada Remaja Putri Kota Bengkulu. Jurnal Kesehatan Masyarakat Andalas, 10(1), 11-18.

Syatriani, S., \& Aryani, A. (2010). Konsumsi Makanan dan Kejadian Anemia pada Siswi Salah Satu SMP di Kota Makassar. Jurnal Kesehatan Masyarakat Nasional, 4(No. 6), 251-254.

Tarwoto. (2010). Kesehatan Remaja Problem dan Solusinya. Jakarta: Salemba Medika.

Tashara, I. F., Achen, R. K, M Quadras, R., D’Souza, M. v., Jyouti, P. J., Sankar, A. (2015). Knowledge and self-reported practices on prevention of iron deficiency anemia among women of reproductive age in rural area. International Journal of Advances in Scientific Research, 1(7), 289-292. https://doi.org/10.7439/ijasr

World Health Organization. (2005). Worldwide Prevalence of Anaemia. WHO Report, 51. https://doi.org/10.1017/S1368980008002 401

World Health Organization. (2011). Haemoglobin concentrations for the diagnosis of anaemia and assessment of severity. Geneva, Switzerland: World Health Organization, 1-6. https://doi.org/2011 